\title{
Caspian Sea Tidal Modelling Using Coastal Tide Gauge Data
}

\author{
Mahmoud Pirooznia, ${ }^{1}$ Seyyed Rouhollah Emadi, ${ }^{2}$ and Mehdi Najafi Alamdari ${ }^{3}$ \\ ${ }^{1}$ Islamic Azad University, North Tehran Branch, Tehran, Iran \\ ${ }^{2}$ Department of Surveying Engineering, Islamic Azad University, South Tehran Branch, Tehran, Iran \\ ${ }^{3}$ Department of Hydrography, Islamic Azad University, North Tehran Branch, Tehran, Iran
}

Correspondence should be addressed to Mahmoud Pirooznia; ma.pirooznia@gmail.com

Received 3 November 2015; Accepted 21 April 2016

Academic Editor: Karoly Nemeth

Copyright (C) 2016 Mahmoud Pirooznia et al. This is an open access article distributed under the Creative Commons Attribution License, which permits unrestricted use, distribution, and reproduction in any medium, provided the original work is properly cited.

The purpose of this paper is to model tidal conditions in the Caspian Sea using data from coastal tide gauges of Anzali, Noshahr, and Neka Ports. Harmonic analysis method was used to identify and examine 40 tidal components. The results illustrate that the annual (Sa) and semiannual solar (Ssa) components on all of the ports listed have the highest range in comparison with the other components which are, respectively, $16 \mathrm{~cm}, 18 \mathrm{~cm}$, and $15 \mathrm{~cm}$ for annual components and $2.8 \mathrm{~cm}, 5.4 \mathrm{~cm}$, and $3.7 \mathrm{~cm}$ for semiannual components.

\section{Introduction}

The gravitational attraction between Earth, moon, and sun has a well-known influence on Earth's ocean levels [1].

Tidal analysis and prediction are the primary steps in the studies of each hydrodynamic and coastal management matter. It is dealing with the analysis of the sea level heights observations using physical and geophysical approaches advanced from experiences or physical reasoning and based on spectral analysis $[2,3]$.

In general, for the modelling of tides, there are three main ways: first is using hydrodynamic models (Laplace differential equations (LTE)), second is empirical modelling, and third is combination of hydrodynamic models and empirical models [4].

Knowing the causes of water level fluctuations of the seas has been one of the major challenges in all scientific fields and attracts the attention of many researches. Oceanic effects, aerologic effects, tides, climate change, and vertical movement of Earth's shell can be noted as five factors that contribute to the impacts of climate change on the water level fluctuations [5].

The prediction is used in science and engineering to confirm the sympathetic of a given phenomenon by stating what its behavior has been till now and will be at a given time and then verifying that it is so [3], although without considering the physical effects of the large events (e.g., tsunami, storms, and seabed earthquake) the prediction of water levels can be achieved [6].

Not only the tides currently are exactly identified in the most global ocean, but also we have learned and computed new features of tidal dynamics [7].

Tidal effects due to their significant impacts on sea water level are of a great importance and researchers have always been looking forward to modelling them [8].

However, numerous undesirable natural events may have an effect on the predictions, but still there are determinable parameters which are essential to handle them exactly; for example, astronomical arguments and nodal corrections are singing the important parts in dealing with tidal analysis and prediction [9].

In this study, the effectiveness of tidal components by the use of coastal tide gauge's observations is surveyed. Harmonic analysis method was used to determine tidal amplitude and phase of 40 components.

(1) Study Area and Relevant Data. Caspian Sea is surrounded by five countries, including Iran, Russia, Azerbaijan, 


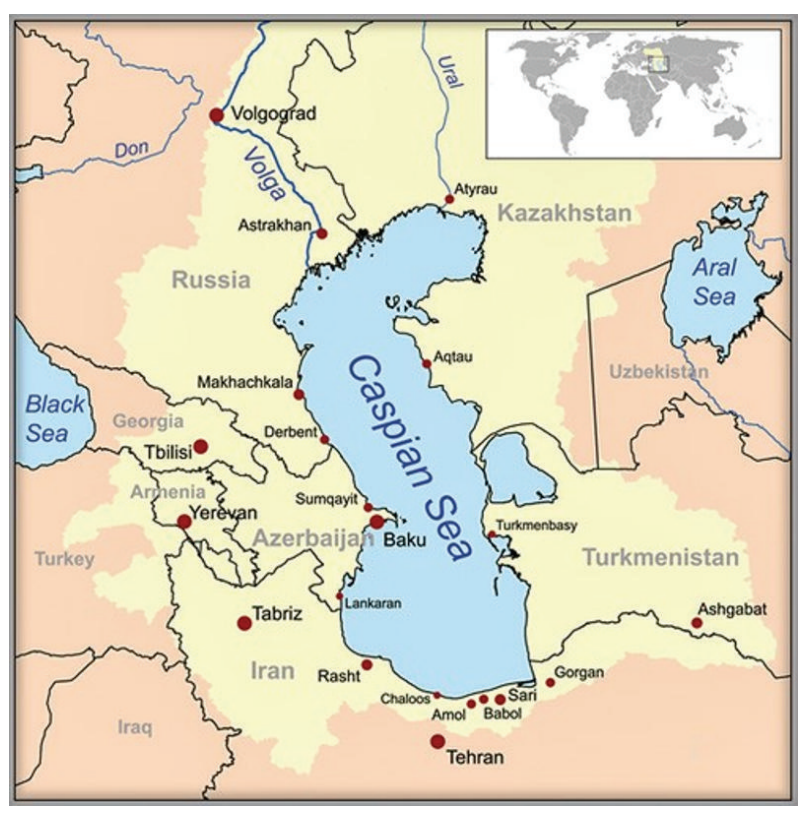

FIgURE 1: Caspian Sea location.

Turkmenistan, and Kazakhstan (Figure 1). The Caspian Sea is the largest remaining section of the old Tethys Sea breakdown that was spread from the Arctic to Indian Ocean through the first to third geological period. In third geological period, appearance of Caucasus and Asian mountains leads to this big Sea dividing, so rise of European continent and construction of Iranian plateau were the main reasons of creation of Caspian Sea. Having the length of about $1030 \mathrm{~km}$ and the width of 435 to $196 \mathrm{~km}$, the Caspian Sea locates between the $47^{\circ} 57^{\prime}$ an $36^{\circ} 33^{\prime}$ circuits and $46^{\circ} 43^{\prime}$ and $54^{\circ} 53^{\prime}$ hour circles [10].

\section{Tides}

Tides are the regular ebbing and flowing movement of the sea happening as the result of attractions of celestial near-earth bodies such as the sun and the moon. Tidal acceleration of celestial objects such as the moon at one point is the difference between the gravity acceleration of that celestial body and the mass centre of the Earth at that point. Viscoelastic earth changes due to tidal forces are roughly one-third of the surface international water. The vector field of these forces can be replaced with a scalar field named potential of tides [11]. [12]

In each point of Earth, this potential can be computed by

$$
U\left(R_{e}, \lambda, \phi\right)=\frac{G M}{R} \sum_{i=2}^{\infty}\left(\frac{R_{e}}{R}\right)^{i} P_{i}(\cos \theta),
$$

where $G$ is the universal constant of gravity, $M$ is the mass of absorbing body (moon or sun), $R_{e}$ is the average radius of Earth, $R$ is the geocentric distance, and $\theta$ is the geological distance of a point with $\left(R_{e}, \lambda, \phi\right)$ coordinates [1]. Main course of this relation is achieved when $i=2$. However, in some cases, $i=3$ is also used for the moon. Thus, the main indicator term of tidal potential is described as follows:

$$
U_{2}\left(R_{e}, \lambda, \phi\right)=\frac{3 G M R_{e}^{2}}{4 R^{3}}\left(\cos 2 \theta+\frac{1}{3}\right)
$$

And regarding spherical trigonometry relations [4],

$$
\begin{aligned}
& U_{2}\left(R_{e}, \lambda, \phi\right)=\sum_{i=0}^{2} U_{2 m}\left(R_{e}, \lambda, \theta\right) \\
& \quad . \frac{3 G M R_{e}^{2}}{4 R^{3}}\left\{\cos ^{2} \phi \cos ^{2} \delta \cos 2 H\right. \\
& \left.+\sin 2 \phi \sin 2 \delta \cos H+\left(1-3 \sin ^{2} \phi\right)\left(\frac{1}{3}-\sin ^{2} \delta\right)\right\} .
\end{aligned}
$$

It can be seen clearly from this relation that the first parameter of the relation relates to the half-daily effects and the second and third parameters, respectively, show the effects of daily and long period of tides. This relationship suggests that the tidal potential is a function of the absorbent body (moon and sun). It should be noted that, except for the gravitational forces mentioned above, other factors may be effective in producing and intensifying the tides [13].

In general, the sea water level fluctuations can be obtained as the result of the interaction of following dynamic processes: tides, changes in atmospheric pressure, the dynamic effects of ocean circulation, wind effects, the effects of temperature, water salinity changes, the effects of river discharge into the oceans, and melting of polar ices.

\section{Tidal Harmonic Analysis}

In this study, the Fourier harmonic analysis method is used to determine the effect of tidal components. As tidal components frequency, water level in each moment and time was given, and the amplitude and phase of needed component were determined [14]:

$$
\begin{aligned}
u(\varphi, \lambda, t)= & \operatorname{MSL}(\phi, \lambda) \\
& +\sum_{i=1}^{n} a_{i}(\Phi, \lambda) \cos \omega_{i} t+b_{i}(\varphi, \lambda) \sin \omega_{i} t
\end{aligned}
$$

where $u(\varphi, \lambda, t)$ is water level in $t$ moment obtained by tide gauge, $\operatorname{MSL}(\phi, \lambda)$ is mean sea level, $\omega_{i}=2 \pi f_{i}$ is angular frequency derived from tidal components frequency, $t$ is the observation time, and $a_{i}$ and $b_{i}$ are the Fourier coefficients we need to determine. Considering (4) and proration, the amplitude and the phase are calculated as 


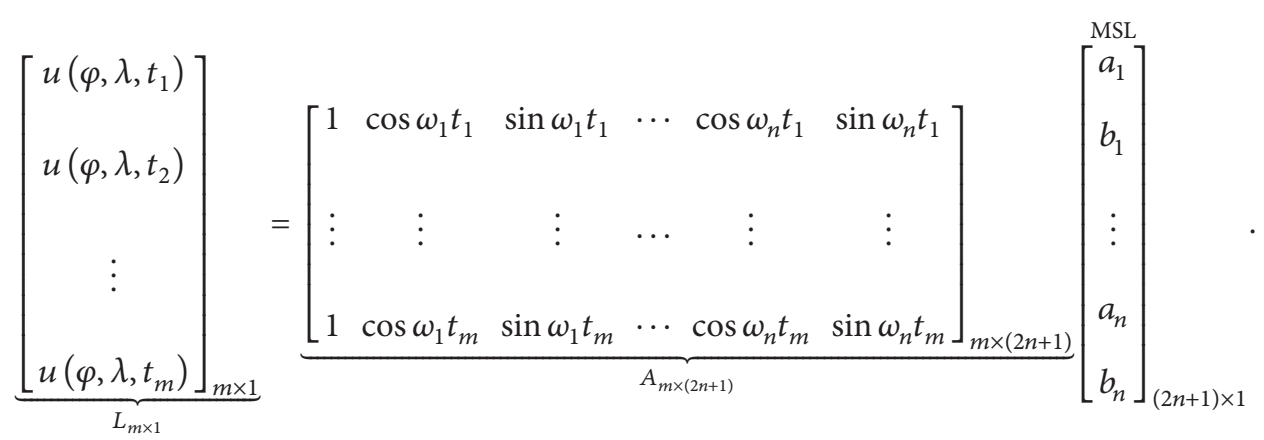

If $m$ was observed value from tide gauge and $n$ was the tidal component, then

$$
A_{m \times(2 n+1)} X_{(2 n+1) \times 1}=L_{m \times 1} .
$$

$A$ is Vandermonde (pattern) matrices [15]. As the result,

$$
\widehat{X}=\left(A^{T} A\right)^{-1} A^{T} L
$$

And the amplitude and phase of tidal components are determined from the following equation $[16,17]$ :

Amplitude:

$$
A_{(i)}=\sqrt{a(i)^{2}+b(i)^{2}} \text {. }
$$

Phase:

$$
\begin{gathered}
\Phi(i)=\tan ^{-1}\left(\frac{b(i)}{a(i)}\right) \\
\text { or } \Phi(i)=2 \tan ^{-1}\left(\frac{b(i)}{A_{(i)}+a(i)}\right) .
\end{gathered}
$$

\section{Tide Modelling}

The following equation is used to analyze and predict the tide $[18,19]$ :

$$
\begin{aligned}
& h(t) \\
& =Z_{0} \\
& +\sum\left[f_{n}(t) H_{n} \cos \left(\delta_{n} t-g_{n}+V_{n}\left(t_{0}\right)+u_{n}(t)\right)\right] .
\end{aligned}
$$

And $n=1,2, \ldots, N$ tidal components.

In the above equation, $Z_{0}$ is the average sea level, $N$ is the number of tidal components, $\delta_{n}$ is angular frequency or speed (degree per hour), $V_{n}\left(t_{0}\right)$ is astronomical argument, $f_{n}(t)$ is nodal factor, $u_{n}(t)$ is nodal phase, $H_{n}$ is the component amplitude, and $g_{n}$ is the phase lag.

In above relations, nodal corrections $\left(f_{n}(t), u_{n}(t)\right)$ for each tidal component and astronomical argument $\left(V_{n}\left(t_{0}\right)\right)$ must be calculated in order to determine the revised amplitude and phase. In this step, $V_{n}\left(t_{0}\right)$ is computed as

$$
\begin{aligned}
V_{n}\left(t_{0}\right)= & i_{b} \lambda_{s}(t)+i_{c} \lambda_{h}(t)+i_{d} \lambda_{p}(t)+i_{e} \lambda_{N}(t) \\
& +i_{f} \lambda_{P^{\prime}}(t)+\Phi_{n}
\end{aligned}
$$

where $\left(i_{b}, i_{c}, i_{d}, i_{e}, i_{f}\right)$ are the constituent's Doodson numbers in which solar coefficients are preferred to lunar coefficients and the desired time is the time data starting in zero hour UT (Universal Time) and remaining terms are as follows:

(i) $\lambda_{s}(t)$ or simply " $s$ " is the Mean Longitude of Moon.

(ii) $\lambda_{h}(t)$ or simply " $h$ " is the Mean Longitude of Sun.

(iii) $\lambda_{p}(t)$ or simply " $P$ " is the Longitude of Lunar Perigee.

(iv) $\lambda_{N}(t)$ or simply " $N$ " is the Longitude of Lunar Ascending Node.

(v) $\lambda_{P^{\prime}}(t)$ or simply " $P$ " " or " $P 1$ " is the Longitude of Perihelion.

(vi) $\Phi_{n}$ is stationary phase (a multiple of $90^{\circ}$ ).

Stationary phase exists in most of Doodson numbers' tables. Algebraic formula to determine the geographic Astronomical Longitude (the Celestial Sphere) $\lambda_{s}(t), \lambda_{h}(t), \lambda_{P}(t)$, $\lambda_{N}(t), \lambda_{P^{\prime}}(t)$ or in some references in form of $\left(s, h, P, N, P^{\prime}\right)$ has been provided $[20,21]$. In this study, Task-2000 method has been used.

Task-2000 is based on zero hour epochs UT, January 1900. This formula is accurate at least from 1800 to 2100 [22]:

$$
\begin{aligned}
& \lambda_{s}(t)=277.0247+129.38481 \cdot \mathrm{IY}+13.17639 \cdot \mathrm{DL}, \\
& \lambda_{h}(t)=280.1895-0.23872 \cdot \mathrm{IY}+0.98565 \cdot \mathrm{DL}, \\
& \lambda_{P}(t)=334.3853+40.66490 \cdot \mathrm{IY}+0.11140 \cdot \mathrm{DL}, \\
& \lambda_{N}(t)=259.1568-19.32818 \cdot \mathrm{IY}-0.05295 \cdot \mathrm{DL}, \\
& \lambda_{P^{\prime}}(t)=281.2209+0.017192 \cdot \mathrm{IY},
\end{aligned}
$$

where

$$
\begin{gathered}
\mathrm{IY}=\text { year }-1900, \\
\mathrm{DL}=\mathrm{IL}+\mathrm{IDAY}-1 .
\end{gathered}
$$




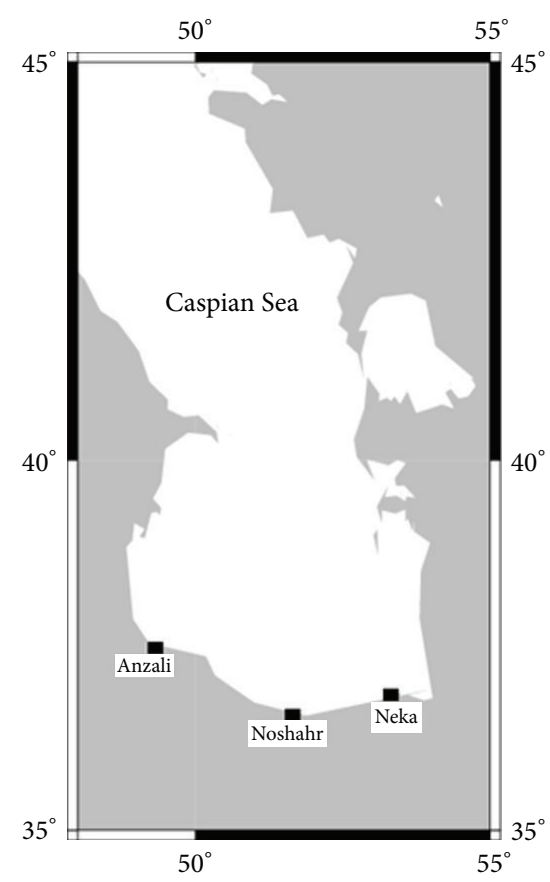

FIGURE 2: Display studied stations.
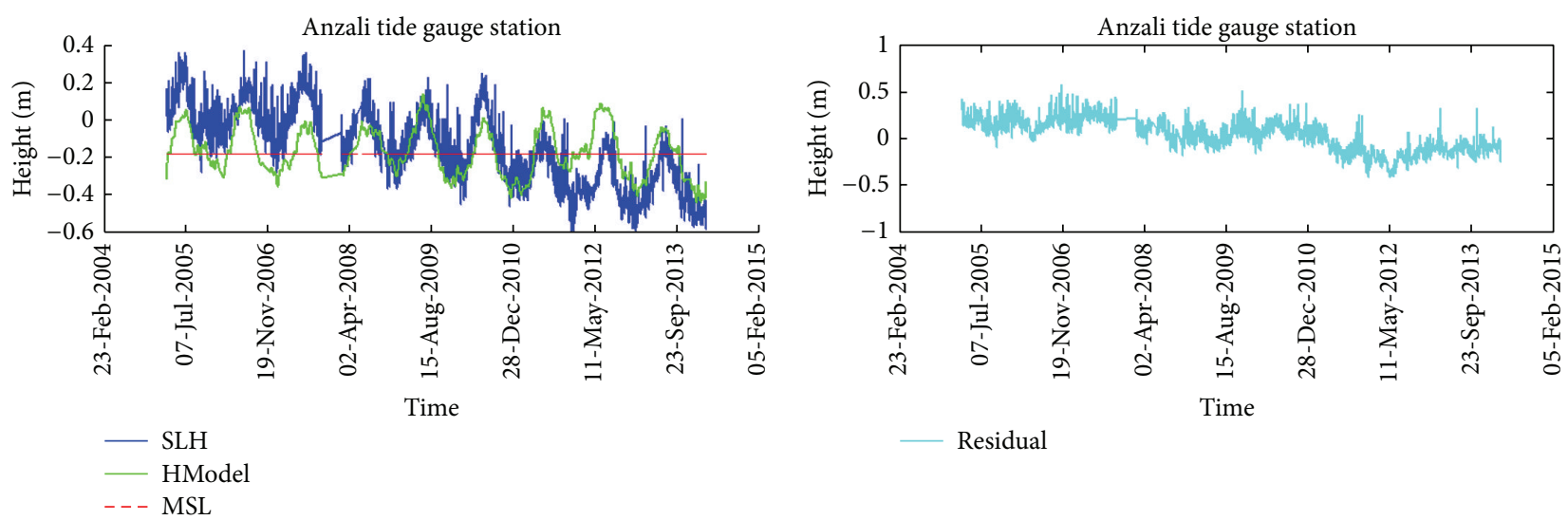

FIGURE 3: Time series along with the tidal modelling and residual of Anzali tide gauge station.

TABLE 1: The location of Caspian Sea coastal tide gauge stations.

\begin{tabular}{lccc}
\hline Station name & Latitude & Longitude & Time spam \\
\hline Anzali & $37.4780^{\circ}$ & $49.4623^{\circ}$ & $21 / 3 / 2005-20 / 3 / 2014$ \\
Noshahr & $36.6584^{\circ}$ & $51.5047^{\circ}$ & $21 / 3 / 2006-21 / 3 / 2014$ \\
Neka & $36.8502^{\circ}$ & $53.3656^{\circ}$ & $1 / 1 / 2000-31 / 8 / 2012$ \\
\hline
\end{tabular}

In this formula, IL is the number of leap years from 1900 onward that is calculated by the following equation:

$$
\mathrm{IL}=\frac{(\mathrm{IY}-1)}{4} .
$$

IDAY is the number of days from January 1st of that year.

\section{Forming the Observations Time Series of Coastal Tide Gauge}

Features of tide gauge stations which are formed from their time series data were in Table 1 and geographical position of tide gauge stations could be seen in Figure 2 .

The analysis of time series Anzali tide gauge station and modelling time series by (10) could be seen in Figure 3. Residuals are small and acceptable. More amplitude to frequency of 40 tidal components of Anzali tidal gauge station could be seen (Figure 4). The values of time series analysis in Anzali station as well as the values of time series modelling analysis are shown in Table 2. It is shown that the modelling was done well. The same process was continued for stations Noshahr and Neka (Figures 5-8). Also, results of time series analysis 


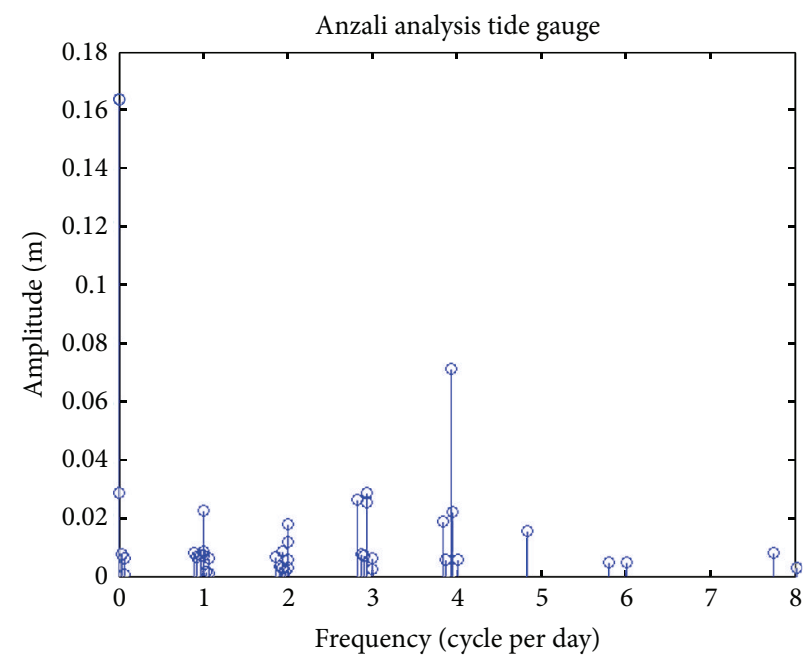

FIGURE 4: Amplitude to frequency of 40 tidal components of Anzali tidal gauge station.
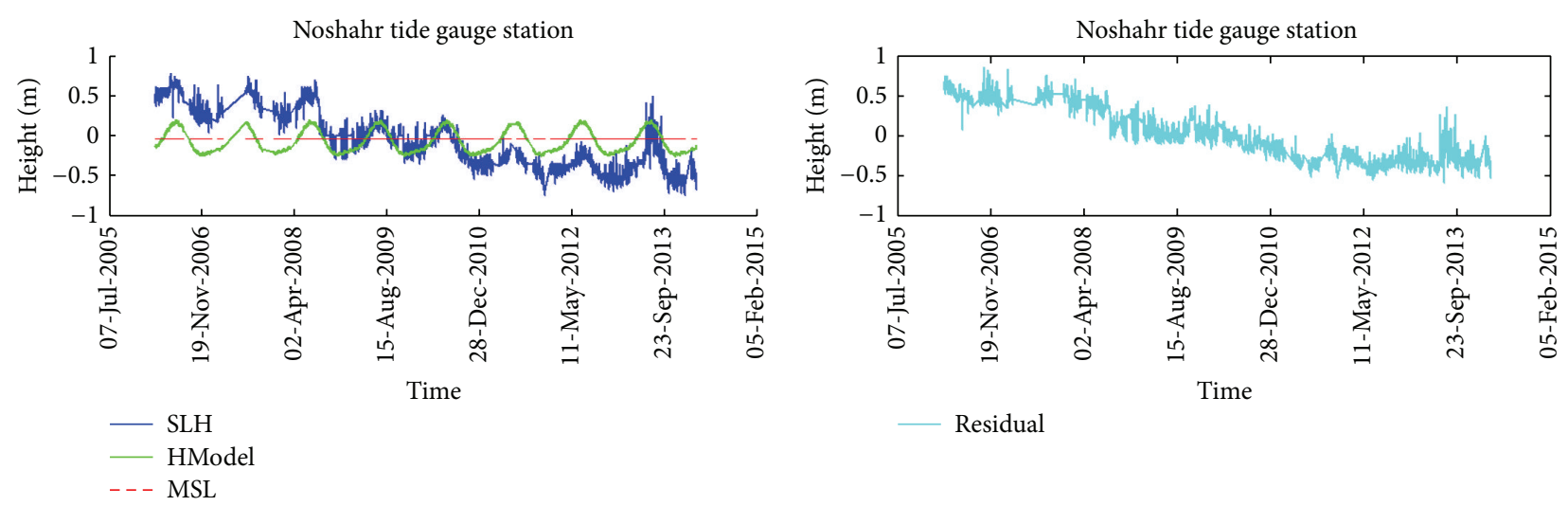

_ Residual

FIGURE 5: Time series along with the tidal modelling and residual of Noshahr tide gauge station.

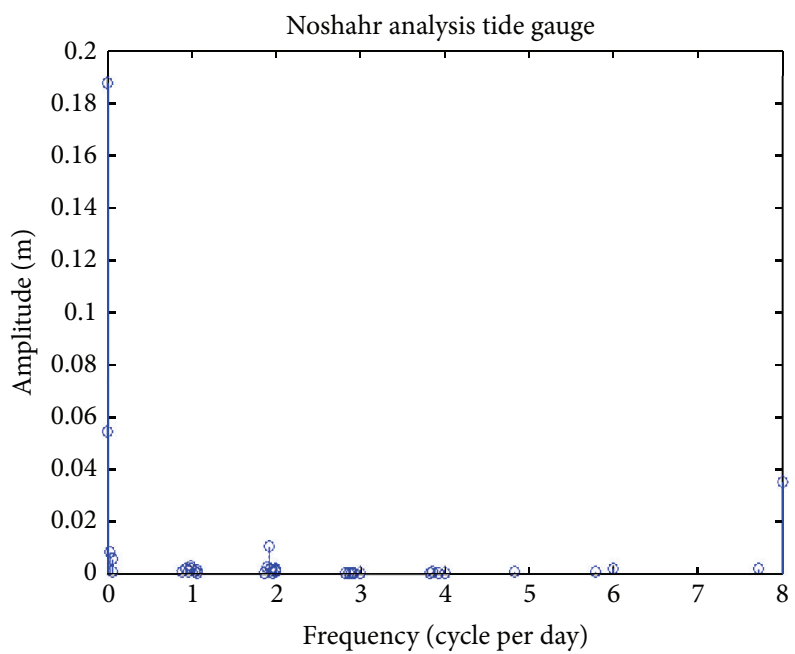

FIgURE 6: Amplitude to frequency of 40 tidal components of Noshahr tidal gauge station. 

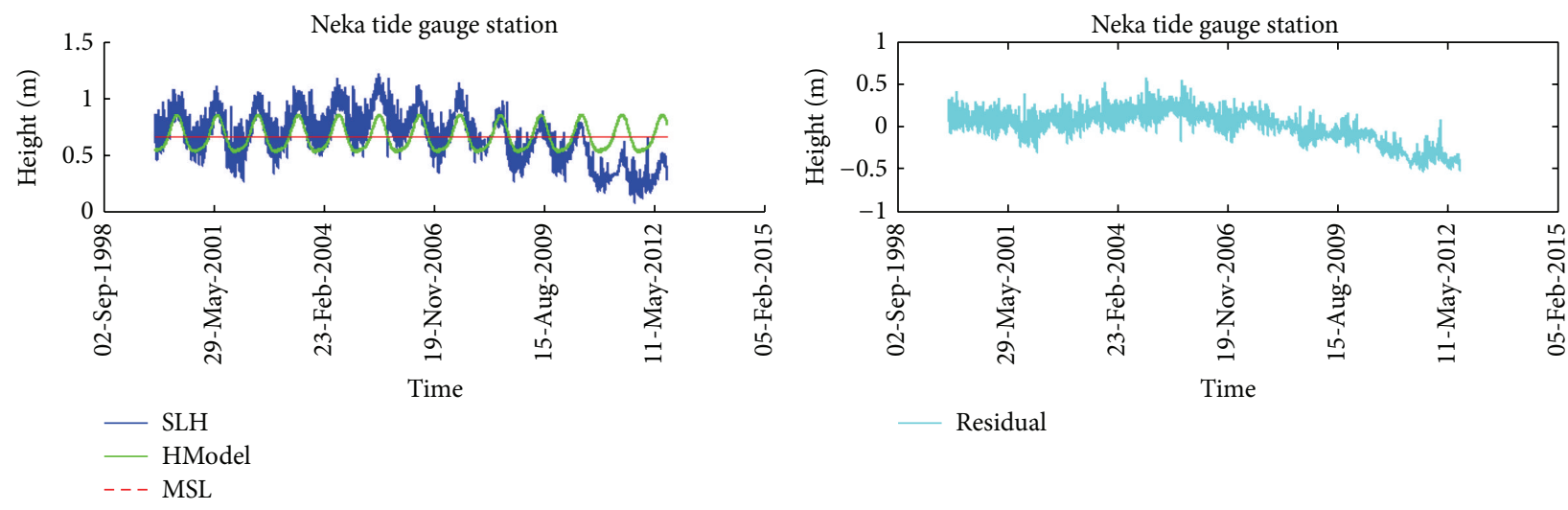

FIgURE 7: Time series along with the tidal modelling and residual of Neka tide gauge station.

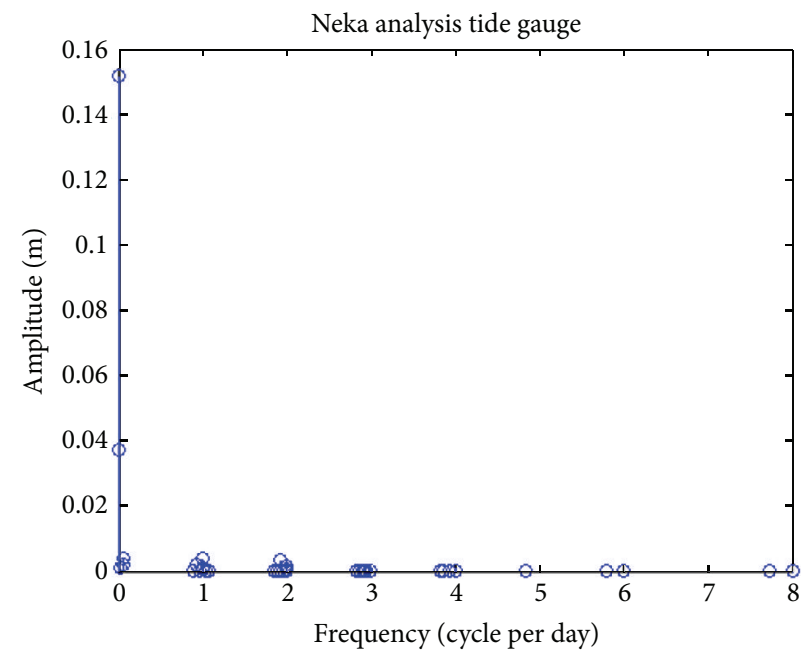

FIGURE 8: Amplitude to frequency of 40 tidal components of Neka tidal gauge station.

and results of time series modelling in stations Noshahr and Neka are shown in Tables 3-4.

\section{Conclusion}

Tidal analysis of tide gauge stations illustrates the absence of efficiency in tidal components except for annual and semiannual components. However, unlike other stations, in Anzali station, MS4 components were effective.

The results also indicate that the annual $(\mathrm{Sa})$ and semiannual solar (Ssa) components on all of the ports listed have the highest range in comparison with the other components which are, respectively, $16 \mathrm{~cm}, 18 \mathrm{~cm}$, and $15 \mathrm{~cm}$ for annual components and $2.8 \mathrm{~cm}, 5.4 \mathrm{~cm}$, and $3.7 \mathrm{~cm}$ for semiannual components.

By comparing the results with other studies [23, 24], the results of tidal analysis of this study are confirmed. The effect of the tides in the Caspian Sea is very small and there are only annual and monthly variations.

In [23], spectral analysis on tide gauge observation of Caspian Sea was done where the annual and semiannual component effect were observed. So it is corresponding with tidal analysis of this study.

Ignoring the modulation of solar perihelion and nodal modulation use can be mentioned as the weak points which were effective in tidal harmonic analysis; 18.6 time series must exist for resolving all frequencies. As for the other defects 
TABLE 2: The amplitude and phase of 40 tidal components for Anzali tide gauge station, obtained from observations and modelling.

\begin{tabular}{|c|c|c|c|c|}
\hline Constituent & Amp_obs (m) & Phase_obs (deg) & Amp_mod (m) & Phase_mod (deg) \\
\hline $\mathrm{K} 2$ & 0.003015 & 295.7626 & 0.00208 & 286.43 \\
\hline L2 & 0.001672 & 271.2841 & 0.00171 & 271.46 \\
\hline M2 & 0.008682 & 269.2956 & 0.0084 & 269.245 \\
\hline $\mathrm{N} 2$ & 0.003698 & 158.6862 & 0.00374 & 159.22 \\
\hline $\mathrm{Ma} 2$ & 0.003133 & 296.7903 & 0.00314 & 296.79 \\
\hline $\mathrm{R} 2$ & 0.017878 & 73.22793 & 0.01812 & 78.22 \\
\hline S2 & 0.012064 & 67.14119 & 0.01206 & 67.141 \\
\hline $\mathrm{T} 2$ & 0.005672 & 144.9542 & 0.0065 & 142.954 \\
\hline $\mathrm{J} 1$ & 0.001707 & 121.5101 & 0.0017 & 121.8201 \\
\hline $\mathrm{K} 1$ & 0.022738 & 11.43623 & 0.0233 & 11.3 \\
\hline M1 & 0.007332 & 67.24207 & 0.0073 & 68.45 \\
\hline $\mathrm{O} 1$ & 0.006945 & 165.1889 & 0.00693 & 165.1923 \\
\hline P1 & 0.00704 & 217.9986 & 0.007245 & 218.43 \\
\hline Q1 & 0.008204 & 232.6201 & 0.008325 & 232.56 \\
\hline S1 & 0.008428 & 83.31833 & 0.008267 & 84.673 \\
\hline M3 & 0.0072 & 93.20983 & 0.00687 & 93.65 \\
\hline S3 & 0.002717 & 119.0538 & 0.00281 & 119.487 \\
\hline M4 & 0.005868 & 233.6994 & 0.00589 & 233.996 \\
\hline S4 & 0.006028 & 85.39538 & 0.006518 & 85.7 \\
\hline M5 & 0.015845 & 21.3593 & 0.01522 & 21.487 \\
\hline M6 & 0.004693 & 239.5097 & 0.00467 & 240.43 \\
\hline S6 & 0.004883 & 193.316 & 0.0049 & 193.76 \\
\hline M8 & 0.008275 & 265.0774 & 0.00865 & 265.9 \\
\hline S8 & 0.003187 & 159.8985 & 0.00376 & 158.34 \\
\hline Mf & 0.006459 & 109.5878 & 0.006217 & 107.789 \\
\hline $\mathrm{Mm}$ & 0.007524 & 134.4543 & 0.00776 & 136.89 \\
\hline Msf & 0.000792 & 77.13807 & 0.000734 & 76.54 \\
\hline Ool & 0.006236 & 355.2012 & 0.006236 & 355.34 \\
\hline Ssa & 0.028563 & 55.42608 & 0.02862 & 53.56 \\
\hline Ms4 & 0.070979 & 15.67987 & 0.0704 & 15.456 \\
\hline Mn4 & 0.018667 & 186.2534 & 0.01889 & 186.789 \\
\hline Mk3 & 0.02533 & 282.7036 & 0.0255 & 282.408 \\
\hline $\mathrm{Sa}$ & 0.163234 & 212.3174 & 0.163198 & 212.456 \\
\hline Mo3 & 0.007534 & 219.1039 & 0.007423 & 218.56 \\
\hline No3 & 0.026181 & 8.642835 & 0.026789 & 9.43 \\
\hline $2 \mathrm{~N} 2$ & 0.006548 & 46.04756 & 0.006437 & 47.13 \\
\hline So3 & 0.028834 & 137.9187 & 0.02889 & 136.67 \\
\hline Sk3 & 0.006522 & 44.34284 & 0.00657 & 44.389 \\
\hline S01 & 0.001092 & 68.53536 & 0.001034 & 68.576 \\
\hline $\mathrm{Mk} 4$ & 0.022139 & 331.8166 & 0.0234 & 331.8834 \\
\hline
\end{tabular}

of this study, we can point out that there is no easy way to indicate the significance of amplitude and phase together with lack of appropriate solution for coastal areas that affects the shape of tidal waves.

In this study, the method of modelling and predicting of sea level is explained. With modelling sea level, the trend of sea level in future will be predicted and it helps coastal management. Also, in areas where effect of tide is high, by having sea level prediction with modelling, tide can be used to assess other factors affecting sea level variations like tsunami, vertical movement of the crust, and so forth.

The main problem with Caspian Sea tide gauge stations data is improper collecting and compiling them. Moreover, the sampling intervals in Anzali and Noshahr tide gauges are daily and each three hours, respectively, that can affect 
Journal of Geological Research

TABLE 3: The amplitude and phase of 40 tidal components for Noshahr tide gauge station, obtained from observations and modelling.

\begin{tabular}{|c|c|c|c|c|}
\hline Constituent & Amp_obs (m) & Phase_obs (deg) & Amp_mod (m) & Phase_mod (deg) \\
\hline $\mathrm{K} 2$ & 0.001265 & 205.3896 & 0.001276 & 204.9 \\
\hline $\mathrm{L} 2$ & 0.000134 & 104.9257 & 0.000144 & 103.89 \\
\hline M2 & 0.010247 & 275.8484 & 0.01028 & 276.896 \\
\hline $\mathrm{N} 2$ & 0.002429 & 110.3829 & 0.002534 & 110.789 \\
\hline $\mathrm{Ma} 2$ & 0.002005 & 73.94501 & 0.002007 & 74.289 \\
\hline $\mathrm{R} 2$ & 0.00083 & 248.9937 & 0.00076 & 249.3397 \\
\hline S2 & 0.001758 & 10.64485 & 0.001777 & 10.5689 \\
\hline $\mathrm{T} 2$ & 0.00104 & 252.2587 & 0.001067 & 252.678 \\
\hline $\mathrm{J} 1$ & 0.000575 & 38.258 & 0.000589 & 38.378 \\
\hline $\mathrm{K} 1$ & 0.003133 & 206.5065 & 0.003145 & 206.45 \\
\hline M1 & 0.000804 & 197.7024 & 0.000809 & 197.745 \\
\hline $\mathrm{O} 1$ & 0.001833 & 74.5144 & 0.001845 & 74.78 \\
\hline P1 & 0.001664 & 171.5155 & 0.001643 & 172.504 \\
\hline Q1 & 0.000887 & 255.0884 & 0.00076 & 255.56 \\
\hline $\mathrm{S} 1$ & 0.002105 & 352.2459 & 0.00167 & 352.214 \\
\hline M3 & 0.000044 & 284.4275 & 0.000245 & 284.545 \\
\hline S3 & 0.000222 & 10.67813 & 0.00678 & 10.63413 \\
\hline M4 & 0.000773 & 269.5824 & 0.00989 & 269.6724 \\
\hline $\mathrm{S} 4$ & 0.000389 & 334 & 0.000567 & 333.89 \\
\hline M5 & 0.000592 & 308.7407 & 0.000345 & 308.437 \\
\hline M6 & 0.000816 & 107.9719 & 0.00424 & 107.901 \\
\hline S6 & 0.001758 & 297.3552 & 0.00987 & 296.9552 \\
\hline M8 & 0.001783 & 300.9042 & 0.00345 & 300.405 \\
\hline S8 & 0.035218 & 128 & 0.03789 & 128.2362 \\
\hline Mf & 0.005655 & 63.45231 & 0.00679 & 64.82 \\
\hline $\mathrm{Mm}$ & 0.008585 & 157.1591 & 0.00567 & 156.2271 \\
\hline Msf & 0.000698 & 171.7511 & 0.000778 & 171.842 \\
\hline Ool & 0.001602 & 126.1866 & 0.00189 & 125.731 \\
\hline Ssa & 0.054341 & 86.44686 & 0.05345 & 86.461 \\
\hline Ms4 & 0.000389 & 142.9945 & 0.00927 & 143.18 \\
\hline Mn4 & 0.000375 & 12.73982 & 0.00678 & 13.7 \\
\hline $\mathrm{Mk} 3$ & 0.000346 & 67.02355 & 0.00345 & 66.425 \\
\hline $\mathrm{Sa}$ & 0.188683 & 208.5804 & 0.18907 & 208.2541 \\
\hline Mo3 & 0.000228 & 52.28991 & 0.00789 & 51.75 \\
\hline No3 & 0.000178 & 216.8859 & 0.000845 & 217.323 \\
\hline $2 \mathrm{~N} 2$ & 0.000519 & 37.64077 & 0.000612 & 37.772 \\
\hline So3 & 0.000414 & 105.4683 & 0.000432 & 105.94 \\
\hline Sk3 & 0.000306 & 334.2423 & 0.000351 & 334.58 \\
\hline S01 & 0.000225 & 195.3219 & 0.000376 & 194.218 \\
\hline $\mathrm{Mk} 4$ & 0.000424 & 74.62624 & 0.000387 & 74.947 \\
\hline
\end{tabular}


TABLE 4: The amplitude and phase of 40 tidal components for Neka tide gauge station, obtained from observations and modelling.

\begin{tabular}{|c|c|c|c|c|}
\hline Constituent & Amp_obs (m) & Phase_obs (deg) & Amp_mod (m) & Phase_mod (deg) \\
\hline $\mathrm{K} 2$ & 0.000609 & 248.292 & 0.00071 & 248.35 \\
\hline L2 & 0.000094 & 210.8618 & 0.000078 & 211.23 \\
\hline M2 & 0.003386 & 211.6024 & 0.00421 & 212.316 \\
\hline N2 & 0.000451 & 33.09812 & 0.000418 & 33.789 \\
\hline Ma2 & 0.000203 & 2.616894 & 0.000206 & 3.269 \\
\hline R2 & 0.00027 & 266.0452 & 0.000261 & 266.169 \\
\hline S2 & 0.001491 & 353.4808 & 0.00152 & 353.724 \\
\hline $\mathrm{T} 2$ & 0.000322 & 84.26617 & 0.000341 & 83.972 \\
\hline $\mathrm{J} 1$ & 0.0002 & 222.6129 & 0.000237 & 222.7034 \\
\hline $\mathrm{K} 1$ & 0.003984 & 232.586 & 0.004112 & 232.213 \\
\hline M1 & 0.000075 & 18.18968 & 0.000087 & 18.226 \\
\hline $\mathrm{O} 1$ & 0.001979 & 22.82131 & 0.002141 & 24.718 \\
\hline P1 & 0.000709 & 221.6676 & 0.000801 & 237.18 \\
\hline Q1 & 0.000071 & 199.8688 & 0.000076 & 200.1073 \\
\hline S1 & 0.001333 & 265.0889 & 0.001343 & 265.623 \\
\hline M3 & 0.000014 & 238.5899 & 0.000017 & 238.3041 \\
\hline S3 & 0.000127 & 71.53864 & 0.000143 & 70.946 \\
\hline M4 & 0.000041 & 106.7546 & 0.000052 & 106.9928 \\
\hline S4 & 0.00007 & 53.35676 & 0.000083 & 53.468 \\
\hline M5 & 0.000036 & 289.5994 & 0.000038 & 289.783 \\
\hline M6 & 0.00004 & 274.9504 & 0.000047 & 275.7935 \\
\hline S6 & 0.000042 & 59.32671 & 0.00004 & 58.87 \\
\hline M8 & 0.000071 & 0.493216 & 0.000082 & 0.78465 \\
\hline S8 & 0.000007 & 343.1489 & 0.000007 & 343.1376 \\
\hline Mf & 0.003968 & 358.5273 & 0.003965 & 357.5186 \\
\hline $\mathrm{Mm}$ & 0.001392 & 37.48796 & 0.001323 & 38.418 \\
\hline Msf & 0.002203 & 332.5874 & 0.002212 & 333.64 \\
\hline Ool & 0.000043 & 172.098 & 0.000043 & 172.487 \\
\hline Ssa & 0.037471 & 90.08432 & 0.0375 & 91.508 \\
\hline Ms4 & 0.000045 & 225.9218 & 0.00005 & 226.5 \\
\hline $\mathrm{Mn} 4$ & 0.000063 & 309.734 & 0.00006 & 310.47 \\
\hline $\mathrm{Mk} 3$ & 0.000063 & 168.7787 & 0.00007 & 169.681 \\
\hline $\mathrm{Sa}$ & 0.151559 & 218.163 & 0.1518 & 217.2045 \\
\hline Mo3 & 0.000028 & 42.31016 & 0.000027 & 43.401 \\
\hline No3 & 0.000055 & 308.456 & 0.000054 & 307.731 \\
\hline $2 \mathrm{~N} 2$ & 0.000032 & 294.6541 & 0.000034 & 295.391 \\
\hline So3 & 0.00005 & 94.33536 & 0.00006 & 95.591 \\
\hline Sk3 & 0.000114 & 73.86118 & 0.000145 & 74.584 \\
\hline S01 & 0.000171 & 47.30391 & 0.000182 & 47.835 \\
\hline $\mathrm{Mk} 4$ & 0.000058 & 116.3563 & 0.000072 & 116.2482 \\
\hline
\end{tabular}

the tidal modelling and will decrease the accuracy of the computation.

\section{Competing Interests}

The authors declare that they have no competing interests.

\section{References}

[1] D. C. Agnew, "Earth tides," in Treatise on Geophysics: Geodesy, pp. 163-195, Elsevier, New York, NY, USA, 2007.
[2] A. T. Doodson, "Appendix to circular-letter No. 4H: the harmonic development of the tidegenerating potential," International Hydrographic Review, vol. 31, pp. 37-61, 1954.

[3] G. Godin, The Analysis of Tides, University of Toronto Press, Toronto, Canada, 1972.

[4] Y. Wang, "Ocean tide modeling in Southern Ocean," Tech. Rep. 471, Department of Civil and Environmental Engineering and Geodetic Science, The Ohio State University Columbu, 2004.

[5] S. Karabil, Determination of sea level trends and vertical land motions fromsatellite altimetry and tide gauge observations at the Mediterranean coast of Turkey [M.S. thesis], Middle East Technical University, 2011. 
[6] F. Wyatt, G. Cabaniss, and D. C. Agnew, "A comparison of tiltmeters at tidal frequencies," Geophysical Research Letters, vol. 9, no. 7, pp. 743-746, 1982.

[7] F. Lyard, F. Lefevre, T. Letellier, and O. Francis, "Modelling the global ocean tides: modern insights from FES2004," Ocean Dynamics, vol. 56, no. 5-6, pp. 394-415, 2006.

[8] PSMSL, 2011, http://www.psmsl.org/.

[9] N. Najib, A. Abedini, and R. Arabsheibani, "Harmonic decomposition tidal analysis and prediction based on astronomical arguments and nodal corrections in Persian Gulf, Iran," Research Journal of Environmental and Earth Sciences, vol. 5, no. 7, pp. 381-392, 2013.

[10] K. Arpe and S. A. G. Leroy, "The Caspian Sea level forced by the atmospheric circulation, as observed and modelled," Quaternary International, vol. 173-174, pp. 144-152, 2007.

[11] P. Vanicek and E. Krakiwsky, Geodesy the concepts, PP. 70-75, 1986.

[12] P. J. Melchior, The Earth Tides, Oxford, 1966.

[13] A. T. Doodson, "The harmonic development of the tidegenerating potential," Proceedings of the Royal Society of London A, vol. 100, no. 704, pp. 305-329, 1921.

[14] S. Consoli, D. R. Recupero, and V. Zavarella, "A survey on tidal analysis and forecasting methods for Tsunami detection," Science of Tsunami Hazards, vol. 33, no. 1, pp. 1-56, 2014.

[15] K. E. Leffler and D. A. Jay, "Enhancing tidal harmonic analysis: robust (hybrid L1 / L2) solutions," Continental Shelf Research, vol. 29, no. 1, pp. 78-88, 2009.

[16] R. Pawlowicz, B. Beardsley, and S. Lentz, "Classical tidal harmonic analysis including error estimates in MATLAB using TDE," Computers \& Geosciences, vol. 28, no. 8, pp. 929-937, 2002.

[17] T. Hou and P. Vaníček, "Towards a real-time analysis of tides," International Hydrographic Review, vol. 71, no. 1, pp. 29-52, 1994.

[18] J. L. Luick, Australian Tidal Handbook, National Tidal Centre, Adelaide, Australia, 2004.

[19] D.-S. Byun and C.-W. Cho, "Exploring conventional tidal prediction schemes for improved coastal numerical forecast modeling," Ocean Modelling, vol. 28, no. 4, pp. 193-202, 2009.

[20] A. T. Doodson, "The harmonic development of the tidegenerating potential," Proceedings of the Royal Society A: Mathematical, Physical and Engineering Sciences, vol. 100, no. 704, pp. 305-329, 1921.

[21] P. Schureman, "Manual of harmonic analysis and prediction of tides, US Coast and Geodetic Survey," Special Publication no. 98, 1971 .

[22] C. Bell, J. M. Vassie, and P. L. Woodworth, POL/PSMSL Tidal Analysis Software Kit 2000 (TASK-2000). Permanent Service for Mean Sea Level, CCMS Proudman Oceanographic Laboratory, Bidston Observatory, UK, 1999.

[23] M. A. Sharifi, E. Forootan, M. Nikkhoo, J. L. Awange, and M. Najafi-Alamdari, "A point-wise Least Squares Spectral Analysis (LSSA) of the Caspian Sea level fluctuations, using TOPEX/Poseidon and Jason-1 observations," Advances in Space Research, vol. 51, no. 5, pp. 858-873, 2013.

[24] V. Mamaev, The Caspian Sea, European Environment Agency, 2015. 

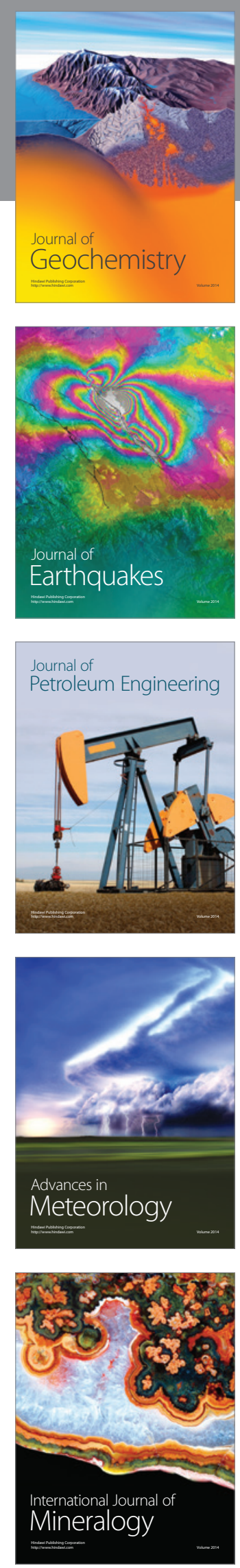
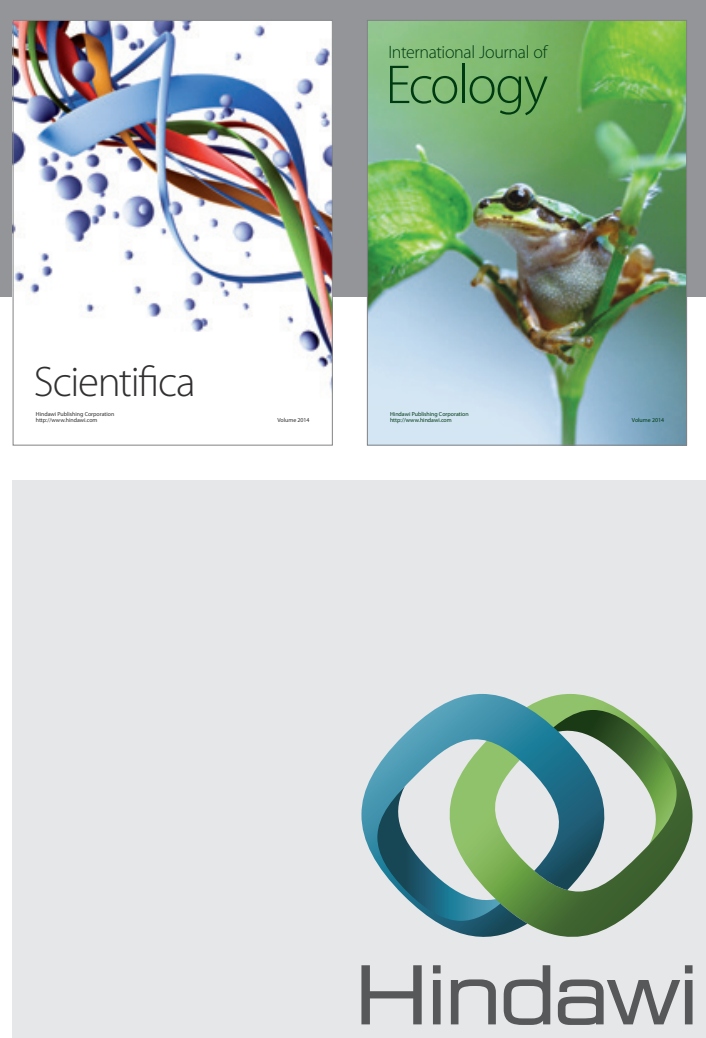

Submit your manuscripts at

http://www.hindawi.com
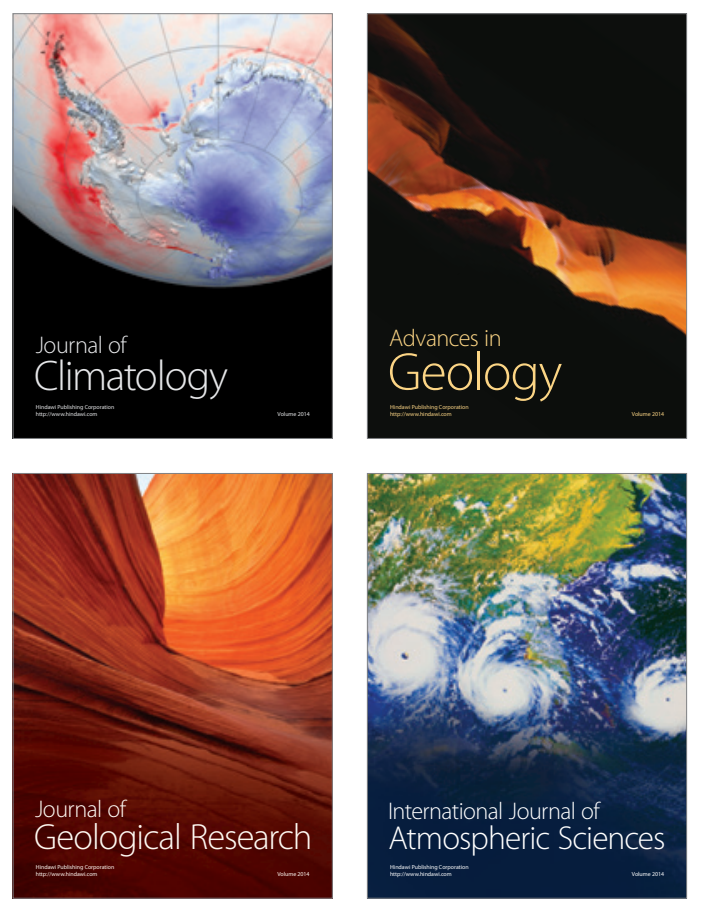

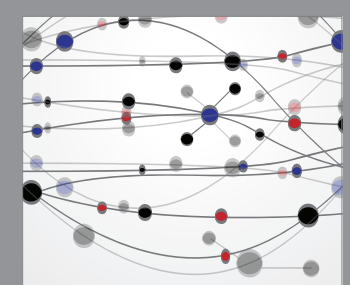

The Scientific

\section{World Journal}
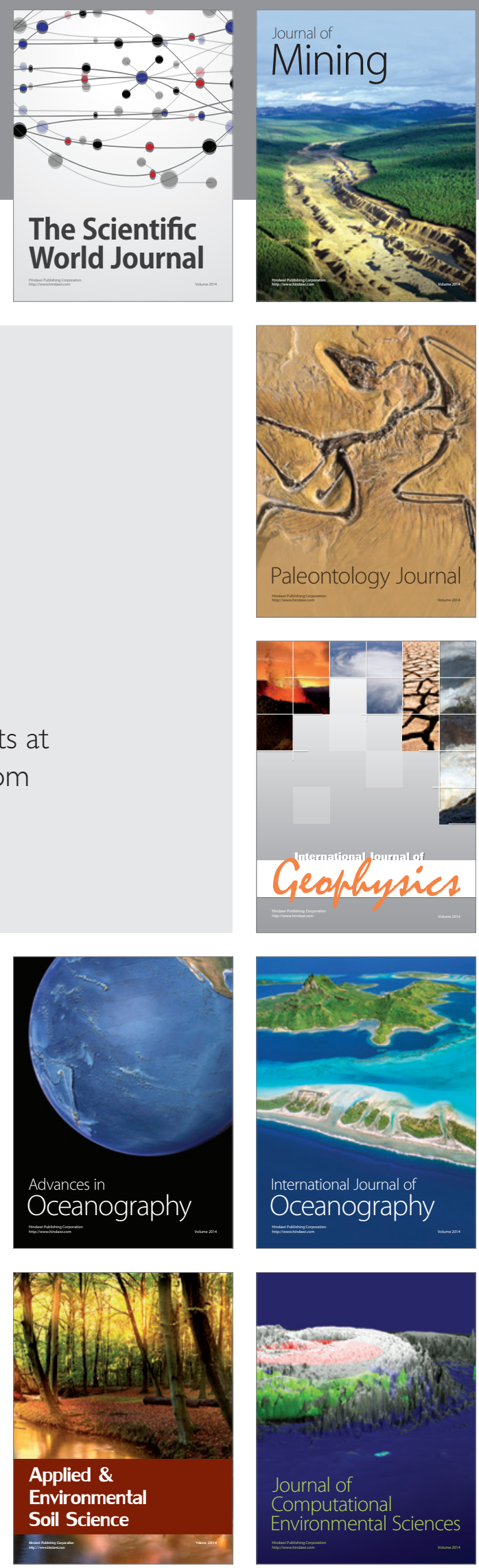